\title{
Moda afro-brasileira: o vestir como ação política
}

Afro-Brazilian fashion: dressing as political action

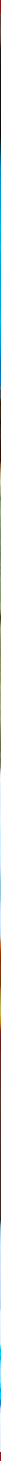


Maria do Carmo Paulino dos Santos ${ }^{1}$

ORCID: https://orcid.org/ 0000-0001-6013-2812

\section{Cláudia Regina Garcia Vicentini ${ }^{2}$}

ORCID: https://orcid.org/ 0000-0002-5059-4271

[resumo] A moda afro-brasileira vem sendo estudada como uma moda contemporânea, que ressignifica conceitos, tradições, comportamentos, modos de fazer e usos no vestir das negras crioulas às negras ativistas em prol do cabelo crespo, que fez do turbante um artefato de resistência negra. 0 objetivo deste artigo é provocar uma reflexão sobre moda afro-brasileira como um vestir político que ressignifica o conceito de luta e resistência a partir da diáspora africana e reafirma a rica contribuição dessa população no fazer da moda brasileira. Para tanto faremos uso do ferramental teórico da semiótica discursiva e dos desdobramentos da sociossemiótica proposta por Eric Landowski, a fim de darmos conta do sincretismo dos discursos figurativizados nas imagens veiculadas em um conhecido veículo de comunicação brasileiro a Revista Veja. A justificativa dessa escolha se dá pelo fato de que a eleição de determinadas figuras por esse destinador, de reconhecido alcance midiático, combinada aos arranjos plásticos presentes nas imagens nos faz refletir sobre esses corpos sociais, permitindo-nos pensar a moda afro-brasileira como uma ação política. Por conseguinte, sugerimos a inclusão do estudo da moda afro-brasileira nos currículos dos cursos de graduação e pós-graduação em Têxtil e Moda e Design de Moda em atenção às leis n. 10.639/2003 e n. 11.645/2008.

[palavras-chave] Moda - aspectos sociais. Moda afro-brasileira. Orgulho crespo. Relações étnicas e raciais. Design de resistência.

\footnotetext{
${ }^{1}$ Doutoranda em Comunicação e Semiótica pela Pontifícia Universidade Católica de São Paulo (PUC-SP). Mestre em Têxtil e Moda pela Escola de Artes, Ciências e Humanidades (EACH) da Universidade de São Paulo. E-mail: mducarmow@gmail.com. Lattes: http://lattes.cnpq.br/1144295437540346.

2 Doutora em Engenharia Mecânica pela Universidade Estadual de Campinas (UNICAMP). Professora Doutora na Escola de Artes, Ciências e Humanidades (EACH) da Universidade de São Paulo (USP). E-mail: claudiagarcia@usp.br. Lattes: http://Lattes.cnpq.br/9606500622271822.
} 
[abstract] The Afro-Brazilian fashion has been studied as a contemporary fashion, which gives new meanings to concepts, traditions, behavior and the ways of doing and using dress of black creoles at black activists in favor of curly hair, which made the turban an artifact of black resistance. The purpose of this article is to provoke a reflection on Afro-brazilian fashion as a political dress that resignifies the concept of resistance fight from the African diaspora, reaffirms the rich contribution of this population in the making of brazilian fashion, since the formation of Brazil. To do so, we will make use of the theoretical tooling of discursive semiotics and the developments of sociosemiotics proposed by Eric Landowski in order to account for the syncretism of the speeches depicted in the images conveyed in a well-known Brazilian media the Revista Veja. The justification for this choice is given by the fact that the choice of certain images by this recipient, of recognized media reach, combined with the plastic arrangements present in the images makes us reflect on these social bodies allowing us to think of Afro-brazilian fashion as an political action. And it suggests the inclusion of the study of Afro-brazilian fashion in the curriculum of undergraduate and graduate courses in textiles and fashion and fashion design in compliance with at laws no.10.639/03 and no.11.645/08.

[keywords] Fashion - social aspects. Afro-brazilian fashion. Curly pride. Ethnic and race relations. Resistance design.

Recebido em: 01-04-2020.

Aprovado em: 17-07-2020. 


\section{Introdução}

O termo moda afro-brasileira tem sido utilizado para designar um vestir contemporâneo, que ressignifica conceitos, tradições, comportamentos e o modo de vida de pessoas negras e não negras - mas que se identificam com esse estilo no vestir. Essa moda está nas ruas, nos eventos periféricos e nas manifestações de resistência de maneira que muitas pessoas se apropriam desse conjunto de elementos estéticos como uma forma de expressão de identidade negra.

Os arranjos plásticos que figurativizam esses valores estão inseridos nos debates das relações étnico-raciais e nas lutas dessa população ao longo da formação do Brasil.

A fim de compreendermos melhor essa complexa rede de significados, delineamos neste artigo um breve relato sobre a moda afro-brasileira e suas incursões desde o período colonial. Pontuamos a presença da mão negra no fazer da moda brasileira no século XVIII, durante o qual homens e mulheres, negros escravizados e forros, confeccionavam finas alfaiatarias, ocupavam-se dos serviços domésticos, das costuras, dos bordados e das rendas com fios de ouro e prata.

A sabedoria e as habilidades das mulheres negras sutilmente atravessou o tempo e está permeado na moda. Elas se tornaram costureiras de peças delicadas e volumosas que exigiam modelagem marcada ao corpo, com um caimento que agradasse a burguesia. As peças desenvolvidas para a classe dominante eram carregadas de sobreposições, detalhes bordados e/ou rendados. Além desse fazer manual, essas mulheres eram habilidosas comerciantes, vendiam tecidos, roupas, especiarias, frutas e os famosos quitutes. Elas também tinham um jeito próprio de se vestir, de se adornar com as joias de crioulas e de modelar os seus turbantes, que são usados até hoje como um símbolo de resistência da mulher negra.

Na atualidade, observamos o uso do turbante em diversos espaços e nas manifestações de resistência negra, como o movimento Orgulho Crespo que foi criado com o mote de enfrentamento do racismo estrutural e em prol da valorização da estética e da identidade negras. A moda afro-brasileira aparece como uma estratégia de visibilidade desse corpo negro ao se manifestar e reivindicar o seu lugar nessa sociedade como sujeito.

O movimento Orgulho Crespo surgiu nas redes sociais a partir de 2014 e, em 2015, ocupou as ruas de diversas cidades brasileiras. Tal alcance angariou o apoio do governo do Estado de São Paulo e resultou na Lei n. 16.682/2018, que instituiu o Dia do Orgulho Crespo.

A moda, como sabemos, legitima padrões estéticos já aceitos socialmente, e segundo Vicentini, Có e Avelar (2020), o corpo é, então, domesticado nesses arranjos estéticos. Ao escravizar o povo negro, a sociedade branca brasileira tentou docilizar esse corpo a fim de submetê-lo às suas vontades e aos seus caprichos. Conforme fala Shucman a ideia de raça está "presente em diferentes experiências da vida social: nas distribuições de recursos e poder, nas experiências subjetivas, nas identidades coletivas, nas formas culturais, e nos sistemas de significação" (SHUCMAN, 2012, p. 13). Apesar de termos no Brasil um discurso que tenta mostrar a miscigenação como um marco positivo da identidade brasileira, o racismo ficou enraizado na sociedade, contribuindo para aumentar as já enormes diferenças socioeconômicas entre negros e brancos. 
Assim, objetivamos, neste artigo, provocar uma reflexão sobre a moda afro-brasileira como um vestir político que ressignifica a resistência do povo negro para além da contemporaneidade, e reafirmar a rica contribuição dessa população no fazer da moda brasileira. Para tanto, faremos uso do ferramental teórico da semiótica discursiva, de Algirdas Julien Greimas, e dos desdobramentos da sociossemiótica proposta por Eric Landowski.

\section{Moda afro-brasileira: breve histórico}

Segundo Santos (2019), a moda afro-brasileira pode ser considerada um fenômeno híbrido da contemporaneidade que agrega, em sua subjetividade, sutilezas das culturas africanas e diaspórica ao receber influência dos movimentos blacks de resistência afro-americano, mesclando objetos e conceitos que perpassam por outras culturas e que estão sendo ressignificados pelos afrodescendentes brasileiros. É nessa teia de grande complexidade que se pode observar a moda afro-brasileira marcando presença em manifestações e eventos que fortalecem a identidade negra.

Segundo Santos (2019), a moda afro-brasileira resgata a herança cultural africana por meio de suas tradições, dos seus usos e costumes, revelando a riqueza de conhecimento do "saber das pessoas" (FOUCAULT, 2016, p. 266) diaspóricas. Esse saber esteve permeado em corpos negros que, ao atravessarem o Oceano Atlântico, transportaram consigo suas riquezas, seus saberes populares: a pluralidade na oralidade, o respeito às ancestralidades, os cultos aos orixás e as crenças religiosas, as técnicas do fazer manual, o cultivo e o beneficiamento do algodão, as costuras de roupas e têxteis, os bordados, os nós e trançados, os usos dos seus turbantes, das joias de crioula, da saia de roda em camadas, do camisú, da cor branca, das cores fortes e quentes, das batas, do decote aberto e arredondado, as ourivesarias (joias artesanais), a marcenaria e a marchetaria (Santos, 2019)

Entre esses fazeres manuais, Araújo (2013) conta que "as mulheres negras impactavam com seus bordados Richelieu, seus panos da Costa, seus banquinhos de bilro e suas sandálias douradas"(ARAÚJ0, 2013, p. 36) e que "homens e mulheres africanos, embarcados da Costa do Marfim com destino ao Brasil, eram tradicionais conhecedores de técnicas de mineração do ouro e do ferro, além de dominarem antigas técnicas de fundição desses metais" (ARAÚJO, 2013, p. 125). Para dar visibilidade a esses saberes, Araújo fala que devemos fomentar na sociedade a discussão sobre a herança e a contribuição do povo negro na formação do Brasil:

A negação do passado científico e tecnológico dos povos africanos e a exacerbação do seu caráter lúdico são algumas das principais façanhas do eurocentrismo, abalando fortemente, ainda hoje, a autoestima da população africana e da diáspora. (ARAÚJO, 2013, p. 33)

Segundo Araújo (2013), o estudo da técnica no Brasil Colônia não pode ser orientado pela história da técnica tal como se desenvolveu na Europa a partir do século XVII por acreditar que esse pensamento se organizou como história das invenções ou como tecnologia, o 
qual seria a descrição dos processos produtivos por meio do discurso lógico e pormenorizado. A partir desse contexto, pode-se dizer que "se justifica uma história da técnica no Brasil, não a partir de uma história de invenções, mas a partir da invenção de uma história [...] ao longo de um período humano" (ARAÚJO, 2013, p. 83-84).

A resistência negra no cenário da moda brasileira foi atravessada por "muitos negros ou pardos engajados nas tropas, já libertos ou escravos, que participaram do movimento considerado como Conspiração dos Alfaiates de 1798" (FLEXOR, 2008, citado por ARAÚJO, 2013, p. 65). E quem eram esses alfaiates? Quem eram as costureiras que foram escravizadas? Como eles faziam as roupas naquela época? Quais técnicas usavam? Segundo Flexor, em suas pesquisas, nos testamentos dos ofícios do período da escravidão, os principais trabalhos dos homens negros que foram escravizados na Bahia eram como alfaiate, barbeiro, cabeleireiro, calafate, carpinteiro, cavouqueiro, oleiro, padeiro, pedreiro e sapateiro. Já as mulheres negras, além dos serviços domésticos, dedicavam-se em sua grande maioria à costura, à renda e ao bordado, mas essas ocupações não eram reconhecidas como um ofício, ao contrário dos alfaiates que eram considerados como artesãos pela exímia qualidade da confecção de suas peças de vestuário, além do que eles costuravam para homens e mulheres com muita sofisticação (FLEXOR, 2008, citado por ARAÚJO, 2013).

As mulheres negras escravizadas ou forras marcaram presença no cenário da moda brasileira no fazer - costurar, bordar e rendar - das roupas no cotidiano do Brasil Colônia; no vestir, ao se adornarem; e como comerciantes. Elas vendiam roupas, tecidos nobres, joias de muito valor, além de outros artefatos. Essas mulheres eram exímias negociantes, algumas se deslocavam de um estado para o outro para fazer negócio com as suas mercadorias. Paiva, citado por Xavier (2012), investigou diversos testamentos deixados por mulheres negras que foram escravizadas e que na condição de forras lavraram seus bens.

Uma delas é dona Joana da Silva Machada, nome de batismo cristão recebido por ser uma pessoa escravizada que veio da Costa da Mina, no continente africano, para o Brasil. Em 1745, a liberta Joana mandou escrever o seu testamento, na Vila de Santo Antônio do Recife, na capitania de Pernambuco. Ela faleceu em 1747, e no espaço de tempo entre a realização de seu testamento e a sua morte, a comerciante se deslocou para fazer negócios de Recife a Minas Gerais, passando pelo estado da Bahia. Sobre os têxteis e a moda deixados por Joana em seu testamento, Paiva descreve:

Seu inventário post-mortem de 1748 arrolavam: tecidos de vários tipos, roupas prontas, lençóis e toalhas, sapatos, fivelas de sapatos [...] Entre roupas de uso, roupas de cama e de mesa, tecidos e sapatos, encontravam-se uma mantilha de veludo guarnecida de renda de prata; saias de primavera preta, de pinhoela preta, de pano azul com seu galão de ouro por baixo, de seda verde, de lã verde, de baeta, de riscadilho "com seu uso" e de "nobreza com muito uso", um capote de camelão forrado de baeta; um colete de galacé (glacê) usado; dois côvados de "pano rosco", 11 de riscadilho, dois de lemiste usado e um de baeta cor-de-rosa; duas varas de Bretanha e quatro entremeio; um chapéu com sua bordadeira, um 
timão de baeta encarnada; uma caixa de moscóvia; dois lençóis com seu entremeio de pano de linho e dois lisos; 11 camisas de Bretanha, cinco de cambraia, e uma "de caça usada", quatro toalhas de pano de linho e uma de Bretanha com sua renda; um lenço branco; dois guardanapos; um gibão de baeta e um chinelo de marroquim com seu uso [...]. (PAIVA, 2012, citado por Xavier, 2012, p. 12-13)

Nessa citação de Paiva, é possível verificar a variedade de tecidos nobres que essa mulher negra na condição de forra comercializava: há uma diversidade de cores e matérias-primas, tecidos pesados e encorpados, bordados em ouro, renda em prata. Trazer à balia todos esses detalhes é fundamental para falarmos da invisibilidade desse fazer negro na moda brasileira que agora passa a ser contado e denunciado pela moda afro-brasileira.

Outra expoente na história, mas que pouco se ouve falar e marca a história ao se adornar com joias de crioula, é dona Folô (figura1). Conforme Factum (2009), dona Folô é a Florinda Anna do Nascimento, a cria da Fazenda Bom Sucesso, em Cruz das Almas, de propriedade do coronel Joaquim Inácio Ribeiro dos Santos e de dona Ana Maria do Nascimento. Ainda segundo Factum, dona Folô "usava a indumentária típica das mulheres da sua condição, mas não era escrava" (FACTUM, 2009, p. 239, grifo nosso). Assim, perguntamos: o que era ser ou não uma escrava? E o que era ser uma cria? Qual era a condição dessa mulher? Ela tinha liberdade sobre o seu próprio corpo? Ela usufruia de liberdade? Ela podia falar não para o seu dono, quando o seu corpo negro era violentado sexualmente? Ela era dona da propriedade em que vivia? Ela pôde gerar e criar os seus filhos nas mesmas condições que a sua patroa?

A questão de ser cria e não escrava, ou seja, uma criada, uma espécie de hierarquia perpetrada pelo "branqueamento"3 (DÁVILA, 2006, p. 53) para discriminar e e/ou classificar os níveis entre as pessoas escravizadas que reforçaram as relações de trabalho escravagista, também se tornou um problema entre os (as) negros (as) para se reconhecerem como tal dentro do contexto social e histórico em que se encontravam, uma vez que esse estado de coisas provocava disputas e rivalidades entre eles mesmos.

A condição de criado era de uma pessoa de confiança, quase um membro da família, mas que na realidade dizia de um escravizado (a) que supervisionava outro escravizado (a). Ou seja, não possuíam de fato uma liberdade plena para gozar sua própria vida como bem quisessem, eles viviam em uma estrutura familiar de controle.

\footnotetext{
3 Sobre o branqueamento, no livro Diploma de brancura: politica social e racial no Brasil - 1917-1945 (DÁVILA, 2006), aborda as questões de eugenia que a sociedade brasileira enfrentou. Nessa leitura, observamos Eduardo Capanema, ministro da Educação e da Saúde em 1938, incomodado com uma estátua do homem brasileiro - que aparentava ser um mestiço. A estátua ficava em frente do prédio do ministério e, segundo o ministro, estava errada pois deveria ser de um homem branco, viril e ariano. Por causa disso, houve todo um esforço do ministro, junto com diversos pesquisadores e cientistas, para tentar mudar biologicamente a genética da população negra brasileira. A intenção deles era transformar todas as pessoas negras e mestiças em brancas (DÁVILA, 2006).
} 


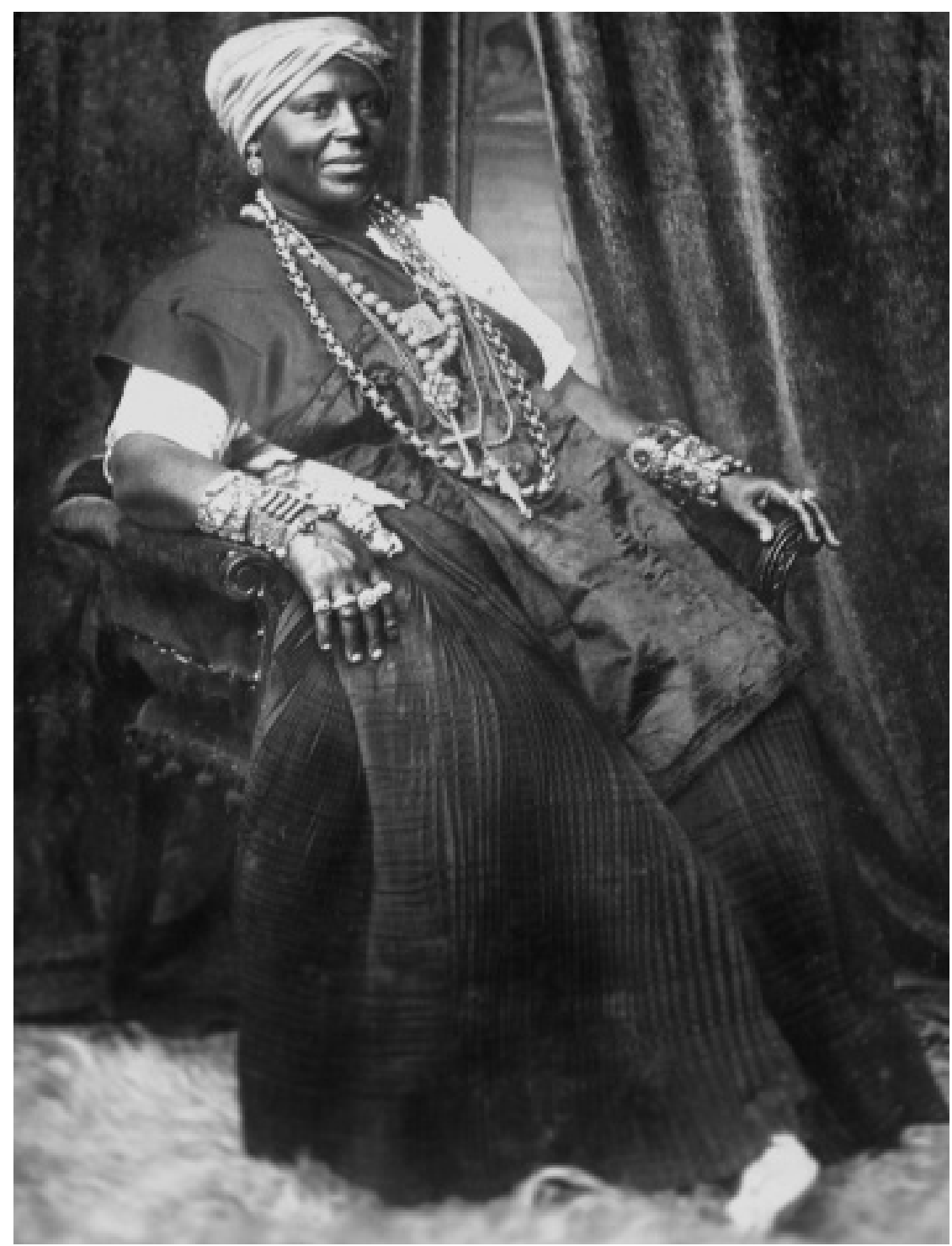

FONTE: FACTUM, Ana Beatriz (2009, p. 239-289). Fotografia de Florinda Anna do Nascimento ${ }^{4}$ integrante do acervo do Museu do Traje e do Têxtil da cidade de Salvador, Bahia.

Nessa imagem, dona Folô faz uso das joias de crioulas, também conhecidas como joalheria escrava baiana. Segundo $\operatorname{Campos}^{5}$ (1925), dona Folô estaria vestida da cabeça aos pés para um momento religioso:

\footnotetext{
4 Florinda Anna Nascimento, segundo Factum (2009), em fotografia do acervo do Museu do Traje e do Têxtil da cidade de Salvador, sem a indicação do autor e da data.

${ }^{5}$ CAMPOS, [...]. [...],1925. Não foi possível encontrar nas referências de Factum (2009) mais informações sobre essa fonte, apenas (Campos, 1925) como segue a citação logo abaixo da imagem.
} 
[...] quando as crioulas se vestiam para ir ver Deus. Elas exibiam seus vestidos pretos pregueados, a mão, turbantes de seda, camisa de um tecido muito fino, admiravelmente bordadas, sandálias de veludo preto ornadas de sequins de ouro e uma profusão incrível de joias caras, nas orelhas, no peito, nos punhos até os cotovelos e nos dedos [...] (CAMPOS, 1925, p.[...] citado por FACTUM, 2009, p. 289).

Dona Folô está carregada de joias de ouro e de prata nos dedos, nos braços, no pescoço; na cintura tem a penca de balangandãs; e na cabeça o turbante que na moda afro-brasileira é considerado um símbolo de resistência negra muito usado pelas ativistas nas manifestações. Outros detalhes que chamam a atenção são a saia de pregas e o sapato marroquim, que nos remetem às peças listadas no testamento de Joana da Silva Machada. Desse modo, imaginamos que ela era uma mulher negra alforriada, por portar essa quantidade de joias, que ostentava seu poder e sua riqueza. Porém, segundo Factum (2009), ela era uma mulher na condição de escrava, usada pelo seu dono como uma espécie de modelo vivo. Ao portarem esses objetos, com a finalidade de exibir suas joias em eventos da "elite na sociedade colonial" (FACTUM, 2009, p. 131), seus escravos domésticos eram como um manequim em encontros e solenidades importantes para ostentar e exibirem seus patrimônios - poder e riqueza:

A joalheria escrava baiana é um conjunto de artefatos votivos, pois estão associados às crenças religiosas de suas usuárias, principalmente as pencas de balangandãs. Também são insígnias de poder quando vinculadas aos senhores de escravos, como modelo de comportamento da elite na sociedade colonial, que adornava suas escravas com uma quantidade exagerada de joias de ouro para exibir poder e riqueza [...]. (FACTUM, 2009, p. 131)

O corpo negro dessas pessoas, que foram usadas como objetos e silenciadas como seres humanos, segue na memória dos afrodescendentes e permeado na trajetória do design de joia, ao qual Factum (2009) e Araújo (2013) propõem que se reconte essa história a partir do reconhecimento da contribuição africana no design de joia brasileiro começando da joalheria escrava baiana.

Factum (2009) investiga a joia de crioula desde dois campos: o concreto e o simbólico. No concreto, analisa a joia escrava como objeto do design, no qual aborda: figuras, formas, matérias-primas, métodos e processos de fabricação, tecnologias, fundições, garimpos e minérios. E destaca que o estado da Bahia, nos séculos XVIII e XIX, foi o centro produtor de "Joias Escravas ou Joias de Crioulas" (FACTUM, 2009, p. 123) e que essas são peças exclusivas do uso das mulheres negras:

No Brasil, a Bahia foi o centro produtor das chamadas Joias Escravas ou Joias de Crioulas [...] Portanto, trata-se de joias que foram elaboradas para uso exclusivo das mulheres negras e mestiças (escravas, alforriadas ou libertas) e são entendidas como objetos do design devido às condições a elas intrínsecas, de projeto, produção, circulação, uso e descarte. (FACTUM, 2009, p. 123) 
Assim, é possível concluir que no passado as negras carregavam as joias de crioula sobre seus corpos e presas às suas vestes como lembranças afetivas de pertencimento à sua cultura africana (FACTUM, 2009). Já no presente as mulheres ressignificam essas histórias e carregam em suas cabeças os turbantes como um símbolo de resistência que exalta as memórias da herança cultural africana e diaspórica.

0 turbante, no campo simbólico, é um adorno de resistência negra que está presente na moda afro-brasileira. Ele também é conhecido como torso, e "pelos praticantes do Candomblé como Ojá Ori - que tem a função litúrgica de proteger o Ori” (PEREIRA, 2017, p. 94). Segundo Pereira (2017), Ori é uma palavra em iorubá que significa cabeça. 0 turbante é um adorno que veio junto com a cultura africana no doloroso processo escravagista, fazendo parte do traje das mulheres negras que, em alguns momentos, utilizavam o turbante e em outros, as tranças.

0 uso do turbante permaneceu ao longo desses 520 anos no Brasil por diversos motivos, entre eles, as questões religiosas, a proteção da cabeça, o respeito aos antepassados e às divindades superiores e a tradição.

No Brasil, com as mulheres negras crioulas, aprendemos a usar turbantes menores no comprimento do tecido e no volume, porém, é possível notar diferenças como, por exemplo, nos africanos descendentes do império de Mali que usavam estilos volumosos, enrolando mais de 40 metros de tecido em cima de suas cabeças para compor seus turbantes - encontramos essa tradição entre os africanos muçulmanos praticantes do Islã que, no Brasil, lideraram o protagonismo pela Revolta dos Malês, em 25 de janeiro de 1835. Kabengele fala sobre a procedência desses africanos muçulmanos no Brasil:

[...] nas pesquisas realizadas para descobrir a procedência dos malês que chega-
vam à Bahia e que foram denunciados nos relatos da revolta dos Malês, os his-
toriadores encontraram: Nagôs, Haussás, Jêjes, Minas, Bornu, Cabinda, Congo,
Gruna ou Grunci e Tapa. (MUNANGA; GOMES, 2016, p. 91)

Com isso, percebemos o turbante como um adorno de cabeça que foi usado ao longo dos tempos e respeitado por diversas identidades religiosas e culturais africanas e pelos os afrodescendentes brasileiros. No Brasil contemporâneo, o turbante permanece como símbolo da resistência negra na composição visual da atual moda afro-brasileira.

\section{Moda afro-brasileira contemporânea}

Essa moda emerge em um momento no qual ativistas negros buscam mostrar à sociedade o quanto ainda são pautados pelo pensamento hegemônico de supremacia branca sobre a população negra. Nesse contexto, o movimento Orgulho Crespo provocou uma ruptura de paradigmas e influenciou o vestir e a valorização da estética e do estilo afro-brasileiro (SANTOS, 2019).

Os negros, então, adotaram essa moda como estratégia política no vestir, uma espécie de "denuncismo" (LOPES, 2015, p. 80). Esses modos de vestir enunciam, e assim, revelam 
a identidade de uma população estigmatizada pelo racismo institucional e estrutural. 0 ativismo busca exaltar o reconhecimento existente entre as "identidades" (HALL, 2009, p. 28) africanas, o sentimento de pertencimento à diáspora e a importância das lutas de resistência da população negra em toda a historiografia social, cultural e política na formação do Brasil.

A expressão "orgulho crespo" nasce nas redes sociais como uma espécie de ativismo em prol da valorização do cabelo crespo como estética negra, impulsionado por um coletivo de blogueiras negras. 0 avanço dessas manifestações começou a ser percebido em 2014 no Brasil, tendo sido influenciado por movimentos semelhantes de outros países.

No Brasil, acreditamos que a mobilização tenha recebido influência de um evento denominado Curl Fest, que acontece no imenso Prospect Park em Nethermead, no Brooklyn (Nova York), nos Estados Unidos, desde 2014, com o slogan The natural hair movement (SANTOS, 2019).

O movimento Orgulho Crespo avançou por todo o território brasileiro. Segundo Malta e Oliveira (2016), esse fenômeno foi impulsionado por meio das redes sociais com o mote orgulho crespo, reunindo especialmente jovens da população negra em números expressivos de seguidores, em diversas cidades brasileiras.

Em 2015, impulsionadas pelas redes sociais, foram organizadas marchas em todo o país com o mote Orgulho Crespo. Elas tinham como objetivo reunir a população negra em prol do orgulho de seus traços étnicos e de sua negritude. Esse espaço reuniu ativistas, militantes sociais, blogueiras que discutem a estética negra etc. 0 aspecto político presente nessa onda de marchas que se sucederam foi impactante. Ele fica mais evidente se levarmos em conta que a fragilização da autoestima da população negra, ocasionada pela ausência de representações positivas de negros e negras na mídia e pela excessiva difusão dos padrões estéticos hegemônicos, está entre os mecanismos mais eficazes do racismo. (MALTA; OLIVEIRA, 2016, p. 65, grifos nossos)

As mídias digitais mostraram força ao convocar, em 2015, a primeira marcha no Brasil que foi para as ruas. A partir dessa comunicação envolvente em rede, as ativistas criaram uma página no Facebook com o nome Movimento Orgulho Crespo e organizaram a Marcha do Orgulho Crespo (figura 2), encabeçada pelo Hot Pente, da jornalista Neomisia Silvestre em parceria com a produtora de moda Thaiane Almeida, junto com o "Blog das Cabeludas, Crespas e Cacheadas", da blogueira Nanda Cury. 0 Hot Pente é um projeto independente e itinerante de festa hip hop que circula pela cidade com o protagonismo feminino. Envolvendo o grafite, a moda e o street dance, que celebra a cultura negra e urbana, visa a valorização da mulher negra no universo do hip hop que, conforme afirmam essas ativistas, sempre foi visto como um espaço totalmente masculino (SANTOS e VICENTINI, 2019).

Sueli Carneiro, filósofa, escritora e ativista na luta pelos direitos das mulheres negras, além de uma das fundadoras do Geledés (Instituto da Mulher Negra), explica que o feminismo negro emerge por dois motivos: falta de espaço para essas mulheres dentro dos movimentos negros e o não-lugar desses sujeitos dentro do feminismo branco. Segundo Djamila 
Ribeiro, "falar a partir das mulheres negras é uma premissa importante do feminismo negro" (RIBEIRO, 2017, p. 35) e reforça que, para elas, é fundamental pensar em saídas emancipatórias que desloquem o pensamento hegemônico para outro lugar, a fim de ressignificar as identidades dando-lhes voz e visibilidade.

[...] pensar em saídas emancipatórias para isso, lutar para que elas possam ter direito a voz e melhores condições. Nesse sentido, seria urgente o deslocamento do pensamento hegemônico e a ressignificação das identidades, sejam de raça, gênero, classe para que se pudesse construir novos lugares de fala com o objetivo de possibilitar voz e visibilidade a sujeitos que foram considerados implícitos dentro dessa normatização hegemônica. (RIBEIRO, 2017, p. 43)

Ribeiro (2017) ressalta que a luta das mulheres negras precisa possibilitar e dar visibilidade à voz dessas pessoas, aos seus discursos, e à importância de ouvi-las. Em prol dessa narrativa, mulheres como Sueli Carneiro, Lélia Gonzales, Patrícia Hill Collins, Isabella Baumfree (conhecida como Sojourner Truth), Grada Kilomba, Giovana Xavier, bell hooks, Joice Berth, entre outras, dialogam com os contextos sociais e as inquietações étnico-raciais e de gênero nos quais estão inseridas as negras.

Portanto, falar de si mesmas a respeito de suas questões raciais, partindo dos seus corpos, de sua essência, sem deixar que outras pessoas não negras assumam esse lugar, é fundamental para que se rompam paradigmas raciais (RIBEIRO, 2017).

A Marcha do Orgulho Crespo assumiu, então, esse lugar de fala e foi importantíssima para garantir a visibilidade que fora negada por tanto tempo ao povo negro. A primeira mobilização aconteceu no domingo, dia 26 de julho de 2015, por volta das 11 horas da manhã, no vão livre do Museu de Arte de São Paulo (Masp), na Avenida Paulista, em São Paulo. Ali formou-se uma grande roda de manifestantes de todas as idades, imprensa (Jornalistas Livres, Globo e a TVT), diversas bandeiras e representações de movimentos negros (Educafro $^{6}$, Unegro ${ }^{7}$ e Uneafro ${ }^{8}$, entre outros), além de movimentos sociais e artistas.

Os ativistas se reuniram para denunciar atos de racismo por causa do cabelo crespo, da cor da pele e do fenótipo negro. A marcha voltou a acontecer em 2016 e em 2017. Da primeira Marcha do Orgulho Crespo, em 2015, surgiu o projeto de Lei n. 1207/2015, criado a partir das reivindicações das organizadoras da manifestação, de autoria da deputada estadual Leci Brandão, assinado pelo governo do estado de São Paulo, que o reconheceu com a Lei n.16.682, de 19 de março 2018, e instituiu o Dia do Orgulho Crespo de São Paulo a ser celebrado todo dia 26 de julho.

\footnotetext{
6 Educação e Cidadania de Afrodescendentes e Carentes. Fonte: www.educafro.org.br. Acesso em: 22 jun. 2019.

União de Negras e Negros e pela Igualdade. Fonte: www.copene2018. Acesso em: 22 jun. 2019.

${ }^{8}$ União de Núcleos de Educação Popular para Negras/os e Classe Trabalhadora. Fonte: Www. uneafrobrasil.org. Acesso em: 22 jun. 2019.
} 
Segundo o manifesto da Marcha do Orgulho Crespo, o movimento tem como objetivo "celebrar a cultura negra e busca fortalecer a estética afro-brasileira como símbolo de identidade e resistência" (ORGULHO CRESPO, 2017c). É um desejo do movimento, "[..] que a cultura do Orgulho Crespo seja capaz de combater o racismo pelo viés estético e que este seja um ponto de partida para que a sociedade compreenda que cabelo não pode nem deve ser motivo de discriminação e/ou exclusão de qualquer oportunidade" (ORGULHO CRESPO, 2017c).

0 movimento apresenta um recorte de gênero e de raça e problematiza a situação da mulher negra no Brasil, destacando fatores como a desigualdade social, o racismo, a falta de visibilidade e de representatividade na mídia e na moda e a escassa oportunidade no mercado de trabalho.

Observamos, a partir dessas manifestações, que em diversas cidades e estados do nosso país, o comportamento e o estilo da moda afro-brasileira vêm demarcando território e disputando narrativas no cenário da moda nacional. A partir de 2015, notamos maior abertura para a participação de modelos negras em capas de revistas de moda de grande circulação nacional, como Vogue, Marie Clarie, ID, Glamour e ELLE, entre outras, e também aumentou a circulação do estilo afro em novas propostas de produtos de moda, como roupas, objetos de design e estilo e em diversos segmentos dessa área.

Essa moda passou a ocupar um espaço central nas manifestações de resistência da população negra que aconteceram na Avenida Paulista nos últimos anos - nas marchas do Orgulho Crespo, da Consciência Negra e no desfile PaulistAfro ${ }^{9}$, como podemos ver algumas imagens abaixo.

FIGURAS 2 e 3 - MANIFESTANTES NA 2aㅡ MARCHA DO ORGULHO CRESPO, EM 2016
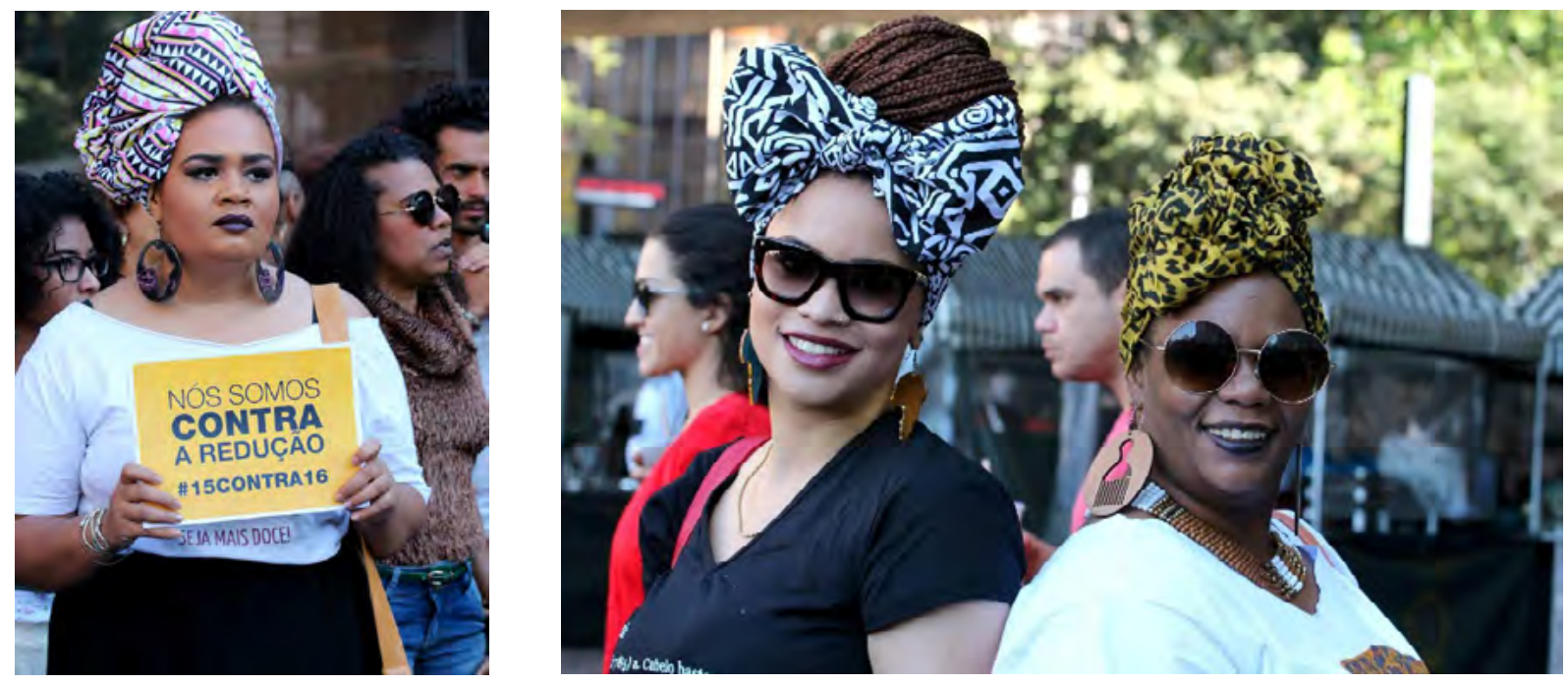

FONTE: Foto de Yui (2016). Álbum de Fotos: Marcha do Orgulho Crespo. Facebook. São Paulo, 2015. Disponível em: https://www.facebook.com/vanderleiyui/media_set?set=a.892222177481855\&type=3. Acesso em: jul. 2019.

\footnotetext{
0 desfile PaulistAfro aconteceu no domingo, dia 17/7/2016, no meio do protesto pelo \#ForaTemer, em defesa da democracia e se posicionando contra o impeachment da ex-presidenta Dilma Rousseff. A organização do desfile foi de Andreia Akilah em parceria com vários coletivos de mulheres negras, entre eles, Educafro e Resistência Democracia, em apoio ao evento \#DomingosContraOGolpe, que foi organizado pelos grupos Resistência, Democracia Corinthiana e CUT-SP.
} 
As figuras 2 e 3 mostram o uso de turbantes, tecidos coloridos e acessórios com a temática afro atualizada para o contemporâneo: os panos estampados, os brincos com silhueta do continente africano e do pente garfo, o colar de contas, os óculos escuros e a t-shirt - todos esses elementos convergem para uma profusão de culturas. 0 código implícito nessas linguagens visuais é aceitação de "ser" negro, o sentimento de pertencimento e identidade negra.

A moda afro-brasileira perpassa por diversos movimentos: na década de 1980, o "break do hip hop" (LOPES, 2015, p. 22) esteve muito presente entre os jovens negros da periferia, que iam para o metrô São Bento ver o artista Nelson Triunfo dançar com seu enorme cabelo black power, vestindo camisa e beca ${ }^{10}$ boca de sino enorme com nesga na lateral. Ali, no vão livre do metrô São Bento, e posteriormente na Galeria do Rock na Rua 24 de Maio, aconteciam eventos que falavam das pautas étnico-raciais por meio da dança, da poesia, da música e do estilo, criando consciência política nos jovens participantes.

Assim, aos poucos, a moda afro-brasileira foi sendo assumida, reforçando essa subversão de ordem social ao possibilitar ao indivíduo que à veste posicionar-se contra a imposição da chapinha e do alisamento nos cabelos das mulheres negras: o uso dos turbantes, os trançados e os diversos estilos de cabelo black, como Angela Davis e os Panteras Negras, na década de 1970, que também influenciaram a moda afro-brasileira. Os cabelos dos negros e negras têm que estar para cima, como dizem as manifestantes ao marchar: "Cabelo armado e nunca penteado!"

Essas características do que é chamada de moda afro-brasileira subvertem a imposição do vestir da moda pautada pelo modelo eurocêntrico branco e magro, uma vez que negros e negras criam e usam roupas amplas, volumosas, coloridas e estampadas com motivos da cultura africana, como o turbante, misturados com elementos da cultura afro-americana.

Comercialmente, o Sebrae de Santa Catarina mostra em seu relatório setorial que o termo moda afro-brasileira, bem como todo esse segmento, vem sendo explorado desde os anos 2000 e é um nicho de mercado composto por vestimentas e acessórios coloridos, alegres, que misturam diversas informações culturais, simbólicas e religiosas. Ressalta ainda que essa moda destaca-se pelas estampas que valorizam a mulher negra por meio da utilização de formas geométricas, do uso de peles, fibras, aplicações, máscaras e símbolos do candomblé, e por influências do grafite e do hip hop. Entre as técnicas empregadas no desenvolvimento das peças, encontra-se a moulage (modelagem tridimensional utilizada como opção na construção do molde), o macramê (com trançados, nós e amarrações), os bordados e a estamparia, entre outras (SIS, 2016).

É possível notar que essa maneira de se vestir está ganhando cada vez mais espaço no guarda-roupa da população negra brasileira, reafirmando o contato com as tradições e os modos de vida de seu povo ancestral.

\footnotetext{
10 Beca é uma expressão popular que significa calça.
} 


\section{A Sociossemiótica}

Segundo Oliveira (2018), a definição de sociossemiótica foi inspirada por Eric Landowski a partir dos estudos de Algirdas Julien Greimas sobre semiótica plástica, figurativa e discursiva. Greimas fala que a semiótica do visual não é, com frequência, um catálogo de nossas falsas evidências por admitir, de início, o seu caráter construído - artificial - e, portanto, isto se opõe às línguas naturais e aos mundos naturais que define como duas macrossemióticas que, indiretamente, nos insere nessa condição de ser um ser humano. Ele sugere-nos pensar a gestualidade natural que acompanha o discurso verbal das linguagens, quando suas formas elementares surgem perante análise como idênticas à visualidade $n a$ tural, observando que se manifesta de maneira transcodificada no interior dos discursos. Ao mesmo tempo que é artificial por se constituir sob a forma de imagens, que é um componente essencial da linguagem poética construída. Nesse sentido, Landowski define a semiótica do visual pelo seu suporte planar, encarregando, assim, a superfície de falar do espaço tridimensional. Com isso, as manifestações imagéticas passam a ser reunidas com base em um modo de presença no mundo comum.

Segundo Castilho e Martins (2014), a sociossemiótica propõe compreender a produção de sentidos na relação sujeito-corpo-roupa, ampliando-as para as questões universais. Nesse contexto, a roupa e o corpo associam-se na expressão do sujeito, acrescentando-lhe orientações de sentido nas conexões que ele estabelece consigo mesmo e com o mundo.

Segundo José Luiz Fiorin (2007), o falante é o suporte das formações discursivas ao construir o discurso, investe nas estruturas sintáticas abstratas, em temas e figuras que materializam valores, carências, desejos, explicações, justificativas e racionalizações existentes em sua formação social. 0 falante é o enunciador, aquele que fala e anuncia. Esse enunciador não é um agente do discurso, mas, é um sujeito paciente e e/ou passivo do discurso. 0 enunciador ou falante é um produto das relações sociais, que assimila uma ou várias formações narrativas existentes em sua concepção política e as reproduz em sua explanação. É nesse sentido que se diz que esse enunciador e/ou falante é um suporte do discurso que reproduz (FIORIN, 2007).

0 agente discursivo é construído à medida em que as formações discursivas materializam as ideológicas, e estas estão relacionadas às classes sociais, portanto, os agentes discursivos são as classes sociais e as frações de classe (FIORIN, 2007).

A semiótica discursiva propõe um percurso gerativo do sentido em que são analisados os dois planos do discurso: o conteúdo e a expressão. No plano do conteúdo, veiculam-se ideias e valores que são concretizados no plano da expressão.

No plano discursivo, vai-se do mais abstrato (nível fundamental), no qual elementos semânticos, tais como liberdade vs. opressão, natureza vs. cultura e outros, são colocados em oposição. No plano narrativo (nível intermediário), essas categorias são colocadas como valores e objetos a serem ou não conquistados. E, por fim, o plano discursivo, o mais concreto de todos, no qual os valores são revestidos de temas e figuras que, segundo Fiorin (2007), são utilizados por uma determinada sociedade em uma época para mostrar distintas visões de mundo (FIORIN, 2007). 
No caso de objetos sincréticos, como os que são estudados neste artigo, em que imagens e textos se misturam, o plano da expressão mostrará os arranjos plásticos eleitos pelo enunciador a fim de concretizar os valores tematizados pelo plano do conteúdo.

Esse plano é caracterizado pela relação entre os formantes, que podem ser cromáticos, eidéticos e topológicos. Os cromáticos mostram as relações entre harmonias cromáticas e seus efeitos de sentido, os eidéticos são relativos às formas de determinados objetos e os topológicos revelam a organização dos outros formantes no espaço pictórico.

Todos os formantes, em relação uns com os outros, corroboram os efeitos de sentido do plano do conteúdo.

\section{Análises}

A mídia é um importante espaço de produção de sentido que ressignifica as práticas culturais e os valores da sociedade, e mais ainda na atualidade, desde que os indivíduos passam cada vez mais tempo navegando na internet e tendo contato com vários meios de comunicação e seus modos de enunciação.

A Revista Veja é um veículo de grande alcance nacional em seus formatos impresso e digital e, segundo dados da Associação Nacional dos Editores de Revistas Brasileiras, é uma das maiores revistas semanais de circulação no país. Conforme Scalzo (2003), é possível conhecer os pensamentos e os valores de uma determinada sociedade por meio de suas revistas.

É um fazer persuasivo que cria efeitos de sentido veridictório, pautado em recursos discursivos nos quais o destinador-manipulador Revista Veja oferece um contrato com o destinatário, uma vez que esse contrato é aceito, o destinatário assume como verdade os dizeres da revista.

Por isso, interessa-nos analisar como foi veiculada a notícia sobra a Marcha do Orgulho Crespo, realizada em 7 de agosto de 2016, já que, como dissemos anteriormente neste artigo, a visibilidade do povo negro nos meios de comunicação historicamente dominados por brancos é muito pequena. Assim, a reportagem mostra, por meio da articulação entre os planos do conteúdo e da expressão, modos de ver o mundo do enunciador. Cabe ressaltar que apenas uma matéria sobre o tema foi veiculada.

A matéria, na página da revista na internet, diz: "Marcha do Orgulho Crespo toma parte da Paulista neste domingo (7)", em negrito. Em seguida, o subtítulo "Segunda edição do movimento, em defesa da cultura negra e dos cabelos crespos, reuniu cerca de 300 pessoas" tem um tamanho bastante reduzido: em poucas palavras e apenas três imagens, é toda informação que se tem sobre o evento ${ }^{11}$.

Dada a importância da marcha para o povo afro-brasileiro, o tamanho reduzido da matéria chama a atenção. Ao nos depararmos com a chamada encabeçada pelo título da matéria, a debreagem enunciativa, nesse caso colocada espacialmente “(...) parte da Paulista

\footnotetext{
11 VEJA SÃO PAULO. Marcha do Orgulho Crespo toma parte da Paulista neste domingo (7). Disponível em: www.vejasp.abril.com/marchadoorgulhocrespo. Acesso em: nov. 2020.
} 
neste domingo (7)" (VEJA SÃO PAULO, 2016), remete-nos imediatamente às manchetes sem as marcas do enunciador, mostrando distanciamento. 0 subtítulo segue as mesmas diretrizes, revelando o distanciamento do enunciador comum nas matérias da revista.

Em seguida está escrito: "Por Veja São Paulo - atualizado em 1 de junho de 2017, 16:02. Publicado em 7 de agosto de 2016, 18:38" (VEJA SÃO PAULO, 2016). Em termos enunciativos, as marcas do enunciador são recuperadas e se coloca o eu/aqui/agora da debreagem enunciativa. Abaixo desse último texto verbal está colocada a imagem:

\section{FIGURA 4 - DESTINADOR-MANIPULADOR REVISTA VEJA}

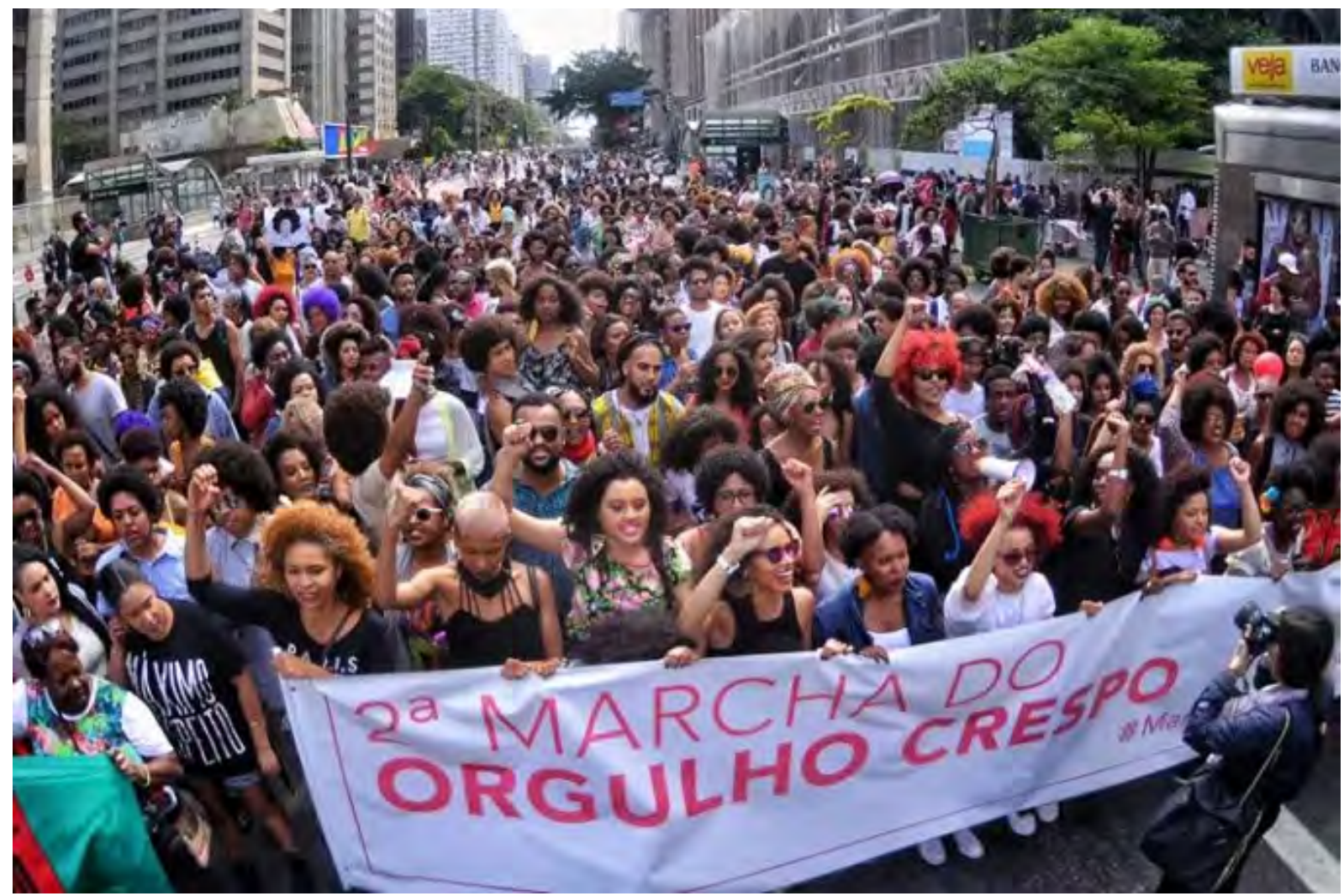

FONTE: Veja São Paulo (2016). Disponível em: https://vejasp.abril.com.br/cidades/marcha-do-orgulhocrespo-toma-parte-da-paulista/. Acesso em: nov. 2020.

O olhar passeia pela figura 4 e o que mais se destaca é o grande número de pessoas na avenida, que se sabe ser a Paulista, importante via de ligação em São Paulo. Topologicamente, o plano da expressão é construído de cima para baixo, remetendo ao efeito de sentido de amplitude, mas também de distanciamento, reiterando o efeito enunciativo do texto verbal escrito do título.

Centralizada na metade inferior da imagem está a faixa branca com dizeres em vermelho, em caixa alta, "2 ${ }^{\underline{a}}$ Marcha do Orgulho Crespo", carregada pelas manifestantes nos diz do que se trata o assunto. Os formantes cromáticos branco vs. vermelho em contraste reiteram o título da reportagem. A imagem como um todo seria impessoal, não fosse por um 
pequeno e importante detalhe: no canto superior direito podemos ver o logotipo da Revista Veja e o começo da palavra banca. Nesse caso, é possível depreender que está em cima de uma banca de jornais. Mas também está na posição daquele que nos mostra o que está acontecendo pela debreagem enunciativa, instaurando um eu/aqui/agora. Aqui, o enunciador Veja se coloca no discurso criando um efeito de sentido de subjetividade, ou seja, quem está mostrando a imagem é o enunciador. Esse recurso é sutil e eficiente ao estabelecer o contrato de veridicção com o enunciatário, que está ligado a um saber-fazer da revista em informar seu público, criando efeitos de sentido de verdade.

Logo em seguida, a matéria diz que a Avenida Paulista foi tomada no domingo por cerca de 300 pessoas, em sua maioria mulheres que participaram da marcha em defesa da cultura negra. Também coloca que foi organizada pelo projeto Hot Pente e pelo Blog das Cabeludas, cujo objetivo é fortalecer a estética afro-brasileira como símbolo de identidade. E continua: "O resultado foi um show de penteados afro de várias cores e tamanhos" (VEJA SÃO PAULO, 2016). Nada é dito sobre a origem do movimento e o objetivo, em poucas palavras, é comunicado como defesa da cultura negra. A ênfase é colocada em "um show de penteados afro" (VEJA SÃO PAULO, 2016) ou seja, o emprego da palavra show remete-nos a algo lúdico e de entretenimento. E, como todo entretenimento, algo supérfluo. Assim, a escolha lexical diz muito sobre o efeito de sentido desejado e, nesse caso, ao associar ao espetáculo, de um modo geral, busca descaracterizar a seriedade do movimento. Reiterando o texto verbal escrito, a imagem que vem a seguir mostra o que o enunciador entende por show.

\section{FIGURA 5 - DISTORÇÃO DA REVISTA VEJA AO REGISTRAR A MARCHA DO ORGULHO CRESPO}

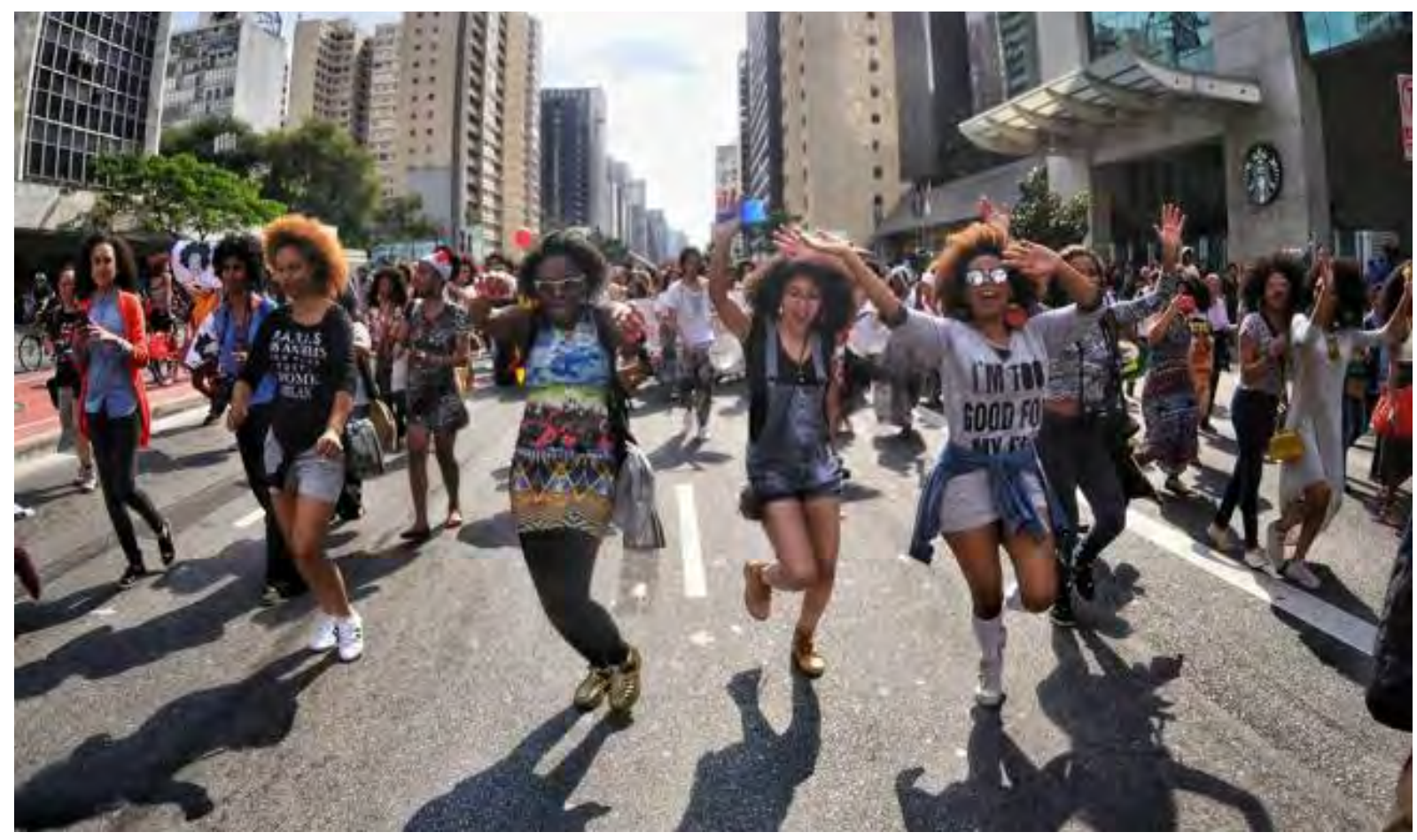

FONTE: Veja São Paulo (2016). Disponível em: https://vejasp.abril.com.br/cidades/marcha-do-orgulhocrespo-toma-parte-da-paulista/. Acesso em: nov. 2020. 
No registro acima, podemos ver quatro mulheres em primeiro plano, a maioria jovem, em poses descontraídas, ostentando o penteado para o qual o enunciador chama a atenção. Essa imagem reitera o efeito de sentido lúdico e, na visão do enunciador, leve e descontraído. Porém, a figura seguinte que ilustra a reportagem mostra-nos algo um pouco diferente. Senão, vejamos.

\section{FIGURA 6 - MARCHA DO ORGULHO CRESPO TOMA PARTE DA PAULISTA NO DOMIGO (7)}

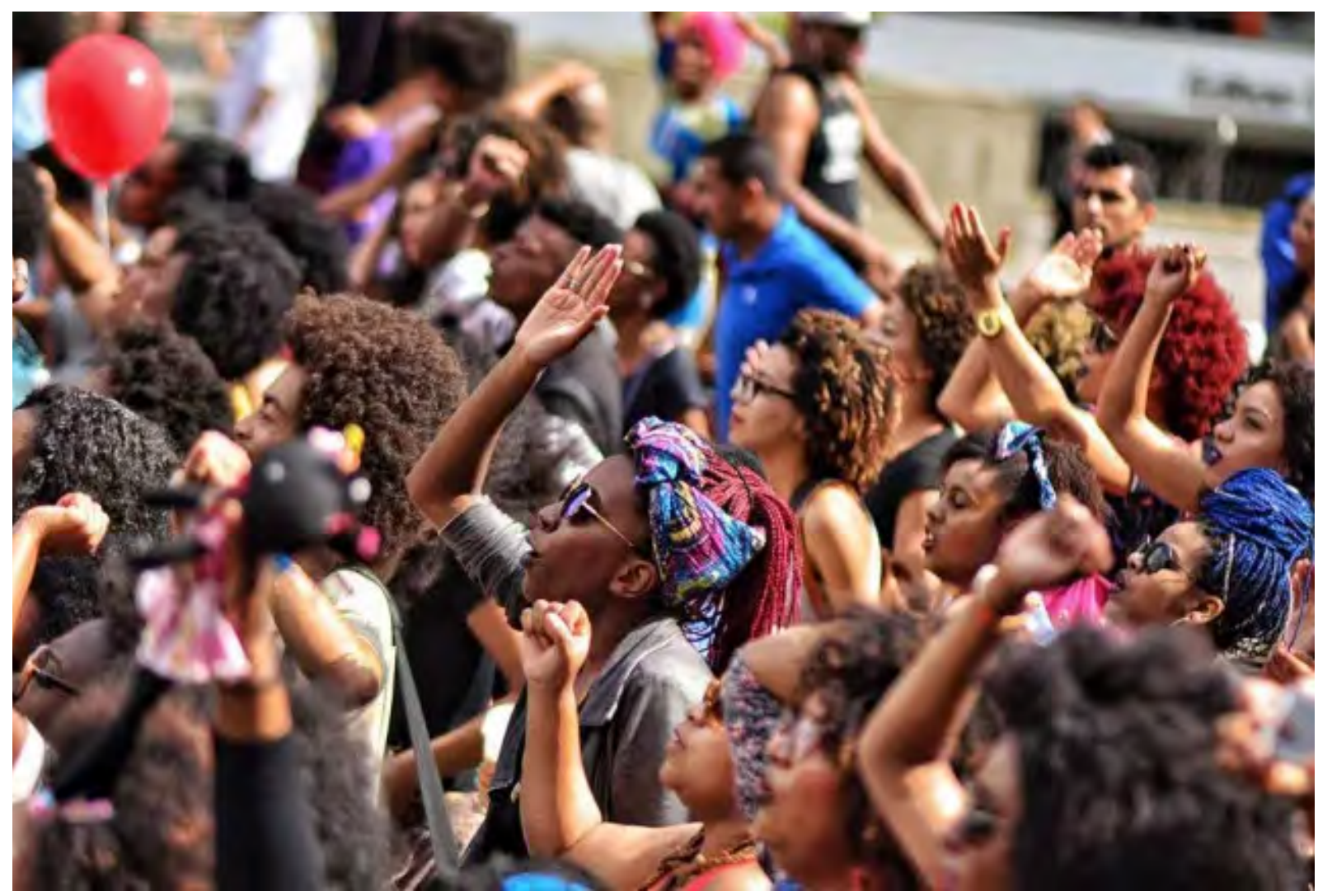

FONTE: Veja São Paulo (2016), Disponível em: https://vejasp.abril.com.br/cidades/marcha-do-orgulhocrespo-toma-parte-da-paulista/. Acesso em: nov. 2020.

Essa fotografia, apesar do formante cromático predominante em seus contrastes, tem na gestualidade seu maior apelo: rostos e mãos levantados e os punhos fechados, signos de determinação e força, contrastam com a ludicidade presentes nos formantes plásticos da imagem anterior. Aqui, mais do que os turbantes e penteados no estilo afro, as palavras de ordem não ouvidas, mas nitidamente pronunciadas pelos rostos em destaque, mostram-nos que, talvez, o simulacro de "show" construído pelo enunciador, não seja, afinal, o único objetivo dessa marcha, mas sim, como dissemos anteriormente, é uma mobilização política em que os padrões vestimentares reiteram o discurso político enunciado pelas mulheres negras.

Continuando a análise, a matéria termina dizendo que estavam previstos mesas-redondas e shows das rappers MC Soffia e Tássia Reis, buscando reiterar o aspecto lúdico do evento. 
Desse modo, podemos deduzir que o destinatário Veja tenta mostrar a Marcha do Orgulho Crespo como um discurso voltado a uma questão estética feminina, descolado do que realmente significa ostentar o cabelo crespo como ele realmente é, um ato político em um contraponto a uma estética branca eurocêntrica que vê nisso um signo de conotação inferior.

Esses discursos estão relacionados com as questões do poder, do direito e da verdade. 0 saber dominado permitiu a Foucault (2016) questionar a ausência de conteúdos históricos que pudessem encontrar a origem dos confrontos sociais e das lutas de classes. É nesse sentido que os discursos e as relações de poder passam pela dualidade percebida no micro e no macropoder. Nas lutas de classe social, o micropoder se fragmenta entre as diversas identidades e ideologias que se relacionam entre si - a essa verdade Foucault denominou de "saber das pessoas" (FOUCAULT, 2016, p. 266), ou seja, conhecimentos e discursos que foram desqualificados na sociedade por se tratar de narrativas construídas por uma classe social que permaneceu sob a hierarquia da classe dominante.

Ao se colocarem em marcha, as mulheres negras mostram muito mais do que suas vestes coloridas, seus cabelos ou seus turbantes, trazem inscritos nesses arranjos plásticos a marca de seu desejo, de poderem assumir sua cor, seu cabelo e suas tradições de forma livre.

\section{Conclusão}

Das análises, podemos depreender que as categorias do nível fundamental do plano do conteúdo da semiótica discursiva - liberdade vs. opressão -, foram tematizadas no texto da revista. Porém, a liberdade foi contextualizada como um entretenimento e reiterada diversas vezes pela escolha imagética do enunciador.

Foi interessante perceber a diferença entre os objetivos da Marcha do Orgulho Crespo e o que foi suscintamente descrito pela revista, corroborando nossas hipóteses iniciais de não visibilidade do povo negro e do vestuário como ação política.

Percebemos que a resistência e o protagonismo das mulheres negras foram impermeáveis ao longo desses 520 anos e se fizeram presentes na atualidade por meio dos corpos sociais das ativistas nas manifestações do povo negro. E nessa luta, tanto no passado como no presente, a moda afro-brasileira, portadora dos signos de liberdade, é ressignificada nos turbantes, nas joias de crioulas, nas saias de roda em camadas, nos bordados, nas rendas, nas estamparias africanas, nos trançados e no cabelo crespo por meio da música, da dança, por carregar a história dessas mulheres negras - crioulas, forras, costureiras, bordadeiras, rendeiras e ativistas que ainda lutam por igualdade de oportunidade.

Essa moda reforça a importância de movimentos como o Orgulho Crespo e as manifestações de resistência, dando visibilidade a esses corpos sociais que enunciam esse vestir cheio de sentidos. Cada vez mais visível, a moda afro-brasileira está em ascensão no Brasil, explorando vários nichos de mercados promissores, que impulsionam o surgimento de produtos e serviços com essa temática: vestuários, calçados, acessórios, cosméticos, plataformas eletrônicas, eventos, mídias, editorias de moda, artesanato, entre outros.

Por isso, acreditamos que o estudo da moda afro-brasileira precisa fazer parte dos currículos dos cursos de graduação e pós-graduação em Têxtil e Moda e Design de Moda em 
atenção à Lei n.10.639/2003 e à Lei n.11.645/2008, que consideram fundamental a inclusão do ensino da história da cultura africana e indígena na Educação Básica. Recomendamos que se estudem a trajetória do protagonismo das negras crioulas na moda brasileira e a alfaiataria feita por alfaiates negros. É importante que se mostre para os alunos de Moda as referências bibliográficas que valorizam o legado do povo negro afro-brasileiro.

\section{Referências}

ARAÚJO, Emanoel. Arte, adorno, design e tecnologia no tempo da escravidão. São Paulo: Museu Afro Brasil, 2013.

BEYDOUN, Suamy. Mulheres participam da $2^{\text {a }}$ Marcha do Orgulho Crespo. G1 SÃo PAULO, São Paulo, 7 ago. 2016. Disponível em:http://g1.globo.com/sao-paulo/noticia/2016/08/mulheresparticipam-da-2-marcha-do-orgulho-crespo-em-sao-paulo.html. Acesso em: ago. 2019.

BRAGA, Alexandre F. Unegro, um projeto de raça, classe e gênero no Brasil. In: CONGRESSO NACIONAL DE PESQUISADORES NEGROS, 10.; (RE) EXISTÊNCIA INTELECTUAL NEGRA E ANCESTRAL: 18 ANOS DE ENFRENTAMENTO, 2018, Uberlândia. [Anais...] Uberlândia: Universidade Federal de Uberlândia, 2018, p. [...].

CASTILHO, Kathia; MARTINS, Marcelo M. Produção de sentidos na relação sujeito-corporoupa. In: FECHINE, Yvanna. (org.). Semiótica nas práticas sociais: Comunicação, Artes, Educação. São Paulo: Estação das Letras e Cores, 2014, p. 235-245.

CURL FEST. Disponível em: https://www.curlfest.com/. Acesso: mar. 2019.

DAVID, Kevin. Mulheres participam da 2 ${ }^{\text {a }}$ Marcha do Orgulho Crespo. G1 SÃo PAULO, São Paulo, 7 ago. 2016. Disponível em: http://g1.globo.com/sao-paulo/noticia/2016/08/mulheresparticipam-da-2-marcha-do-orgulho-crespo-em-sao-paulo.html. Acesso em: ago. 2019.

DÁVILA, Jerry. Diploma de brancura: política social e racial no Brasil - 1917-1945. Trad. Claudia Sant’Ana Martins. São Paulo: Editora Unesp, 2006.

FACTUM, Ana B. S. Joalheria escrava baiana: a construção histórica do design de joias brasileiro. 2009. 335 f. Tese (Doutorado em Design e Arquitetura) - Faculdade de Arquitetura e Urbanismo da Universidade de São Paulo, São Paulo, 2009.

FAGA, Cris. Mulheres participam da $2^{\text {a }}$ Marcha do Orgulho Crespo. G1 SÃo PAULO, São Paulo, 7 ago. 2016. Disponível em: http://g1.globo.com/sao-paulo/noticia/2016/08/mulheresparticipam-da-2-marcha-do-orgulho-crespo-em-sao-paulo.html. Acesso em: ago. 2019.

FIORIN, José L. Linguagem e ideologia. 8. ed. rev. e atual. São Paulo: Ática, 2007. 
FLEXOR, Maria H. O. Os ofícios mecânicos e os escravos. In: ARAÚJO, E. Arte, adorno, design e tecnologia no tempo da escravidão. São Paulo: Museu Afro Brasil, 2013, p. 51-73.

FOUCAULT, Michel. Microfísica do poder. Organização, introdução e revisão técnica de Roberto Machado. 4. ed. Rio de Janeiro: Paz e Terra, 2016.

GOMES, Nilma L. Trajetórias escolares, corpo negro e cabelo crespo: reprodução de estereótipos ou ressignificação cultural? Revista Brasileira de Educação, [...], n. 21, p. 4151, set./out./nov./dez. 2002.

HAGER, Patrícia H. C. Consumo e discriminação étnico racial: considerações sobre o mercado de moda-afro-brasileira. Revista Percurso, Maringá, v. 8, 2016, p. 87-109.

HALL, Stuart. Da diáspora e meditações culturais. Org. Liv Sovik. Trad. Adelaine la Guardia Resende [et al.]. 1ª edição atualizada. Belo Horizonte: Editora UFMG, 2009.

INSTITUTO DE PESQUISA ECONÔMICA APLICADA. Retrato das desigualdades de gênero e raça. Instituto de Pesquisa Econômica Aplicada-IPEA... [et al.]. 4. ed. Brasília: Ipea, 2011. 39 p.: il. Com a participação de: ONU Mulheres, Secretaria de Políticas para as Mulheres (SPM), Secretaria de Políticas de Promoção da Igualdade Racial (Seppir).

LIMA, Dulcilei C. Tá na cabeça, tá na web! Significados simbólicos e historicidade do uso do turbante no Brasil. Revista dObra[s], v. 10. n. 22. nov. 2017, p. 21-41.

LOPES, Charleston R. S. Racionais MC's: do denuncismo deslocado à virada crítica (1990 a 2006). 2015. 119 f. Dissertação (Mestrado em Letras) - Faculdade de Filosofia, Letras e Ciências Humanas da Universidade de São Paulo, São Paulo, 2015.

KOFES, Suely (org.). Gênero e raça em revista: debate com os editores da revista Raça Brasil. Campinas, São Paulo. Cadernos Pagu, jun./jul.,1996, p. 241-296.

MALTA, Renata B.; OLIVEIRA, Laila. T. B. de. Enegrecendo as redes: o ativismo de mulheres negras no espaço virtual. Revista GÊNERO, Niterói, v.16, n. 2, p. 55-69. 1. sem. 2016.

MARCHA DO ORGULHO CRESPO BRASIL. Disponível em: https://www.facebook.com/ orgulhocrespobrasil/. Acesso: jan. 2019.

MUNANGA, Kabengele; GOMES, Nilma. L. 0 negro no Brasil de hoje. 2. ed. São Paulo: Global, 2016.

MUNANGA, Kabengele. Algumas considerações sobre "raça", ação afirmativa e identidade negra no Brasil: fundamentos antropológicos. Revista USP, São Paulo, n. 68, dez./fev. 20052006, p. 46-57. 
OLIVEIRA, Ana C. (org.). Semiótica do social. Barueri: Estação das Letras e Cores, 2018. PAIVA, Eduardo. F.; ANASTASIA, Maria. J. (orgs.). 0 trabalho mestiço: maneiras de pensar e formas de viver - séculos XVI a XIX. São Paulo: Annablume / PPGH/UFMG, 2002.

PAULO, Paula P. Mulheres dão adeus ao alisamento e assumem cachos e o orgulho crespo. G1 SÃo PAULO. São Paulo, 7 ago. 2016. Disponível em: http://g1.globo.com/sao-paulo/ noticia/2016/08/mulheres-dao-adeus-ao-alisamento-e-assumem-cachos-e-o-orgulhocrespo.html. Acesso em: ago. 2019.

PEREIRA, Hanayrá N. O. 0 axé das roupas: indumentária e memórias negras no candomblé angola do Redanda. 2017. 132 f. Dissertação (Mestrado em Ciências Sociais) - Pontifícia Universidade Católica de São Paulo, São Paulo, 2017.

REIS, João J. Rebelião escrava no Brasil: a história do levante dos malês em 1835. São Paulo: Companhia das Letras, 2003.

SANTOS, Maria C. P. Moda afro-brasileira, design de resistência: o vestir como ação política. 2019. 160 f. Dissertação (Mestrado em Têxtil e Moda). Escola de Artes, Ciências e Humanidades da Universidade de São Paulo, São Paulo, 2019.

SANTOS, Maria C. P; VICENTINI, Cláudia R. G. A moda afro-brasileira na marcha do orgulho crespo: regimes de visibilidade. In: BERTOSO, L. S. (org.). Na estante da moda. São Paulo: Ed. Athena, 2019.

SÃO PAULO. Lei n. 16.682, de 19 de março de 2018. Institui o Dia o Orgulho Crespo de São Paulo. Diário Oficial Estado de São Paulo, São Paulo, SP, 20 mar. 2018, v. 128, n. 51. SACALZO, Marilia. Jornalismo de revista. São Paulo: Contexto, 2003.

SCHUMAHER, Schuma; VITAL BRAZIL, Eric. Mulheres negras do Brasil. Rio de Janeiro: Senac Nacional, 2007.

SCHUCMAN, Lia V. Entre o encardido, o branco e o branquíssimo: raça, hierarquia e poder na construção da branquitude paulistana, 2012. [...] f. Tese (Doutorado em Psicologia) - Instituto de Psicologia da Universidade de São Paulo, São Paulo, 2012.

SILVA JR, Hedio. (org.). Diversidade étnico-racial e pluralismo religioso no município de São Paulo. Secretaria Municipal de Promoção da Igualdade Racial-SMPIR. São Paulo: Centrografica, 2016.

SILVIA, Simone T. V. Referencialidade e representação: um resgate do modo de construção de sentido nas pencas de balangandãs a partir da coleção Museu Carlos Costa Pinto. 2005. 210 f. Dissertação (Mestrado em Artes Visuais) - Escola de Belas Artes da Universidade Federal da Bahia, Salvador, 2005. 
SIS. Sistema de Inteligência Setorial. Moda africana no Brasil. Boletim de Tendências: SEBRAE-SC. fev. 2016.

VEJA SÃO PAULO. Marcha do Orgulho Crespo toma parte da Paulista neste domingo (7): segunda edição do movimento, em defesa da cultura negra e dos cabelos crespos, reuniu cerca de 300 pessoas. 7 de ago. 2016. Disponível em: www.vejasp.abril.com/ marchadoorgulhocrespo. Acesso em: nov. 2020.

VICENTINI, Cláudia. R. G.; CÓ, Yasmin.; AVELAR, Suzana. Discursos políticos na moda: o coletivo Estileras, uma análise semiótica. In: Moda Palavra Periódico, v. 13, n. 29, 2020. Disponível em: http://www.revistas.udesc.br/index.php/modapalavra/issue/view/701.

YUI, Vanderlei. Álbum de Fotos: Marcha do Orgulho Crespo. Facebook.

São Paulo, 2015. Disponível em: https://www.facebook.com/vanderleiyui/media_ set?set=a.892222177481855\&type=3. Acesso em: jul. 2019.

XAVIER, Giovana; FARIAS, Juliana B.; GOMES, Flávio (orgs.). Mulheres negras no Brasil escravista e do pós-emancipação. São Paulo: Selo Negro, 2012. 